\title{
Trace Element and Mineral Levels in Serum, Hair, and Urine of Obese Women in Relation to Body Composition, Blood Pressure, Lipid Profile, and Insulin Resistance
}

\author{
Alexey A. Tinkov ${ }^{1}$, Paweł Bogdański ${ }^{2}{ }^{\circledR}$, Damian Skrypnik ${ }^{2}{ }^{\circledR}$, Katarzyna Skrypnik $^{3}$, Anatoly V. Skalny ${ }^{1}$, \\ Jan Aaseth ${ }^{4}$, , Margarita G. Skalnaya ${ }^{1}$ and Joanna Suliburska ${ }^{3, *}$ \\ 1 Laboratory of Ecobiomonitoring and Quality Control, Yaroslavl State University, Sovetskaya St., 14, \\ 150000 Yaroslavl, Russia; tinkov.a.a@gmail.com (A.A.T.); skalny3@microelements.ru (A.V.S.); \\ skalnaya@yandex.ru (M.G.S.) \\ 2 Department of Treatment of Obesity, Metabolic Disorders and Clinical Dietetics, \\ Poznań University of Medical Sciences, Szamarzewskiego St. 84, 60-569 Poznań, Poland; \\ pbogdanski@ump.edu.pl (P.B.); damian.skrypnik@gmail.com (D.S.) \\ 3 Department of Human Nutrition and Dietetics, Poznan University of Life Science, ul. Wojska Polskiego 31, \\ 60-624 Poznan, Poland; katarzyna.skrypnik@up.poznan.pl \\ 4 Department of Research, Innlandet Hospital Trust, 2380 Brumunddal, Norway; jaol-aas@online.no \\ * Correspondence: joanna.suliburska@up.poznan.pl
}

Citation: Tinkov, A.A.; Bogdański, P.; Skrypnik, D.; Skrypnik, K.; Skalny, A.V.; Aaseth, J.; Skalnaya, M.G.; Suliburska, J. Trace Element and Mineral Levels in Serum, Hair, and Urine of Obese Women in Relation to Body Composition, Blood Pressure, Lipid Profile, and Insulin Resistance. Biomolecules 2021, 11, 689. https:// doi.org/10.3390/biom11050689

Academic Editor: Vladimir N. Uversky

Received: 9 April 2021

Accepted: 2 May 2021

Published: 4 May 2021

Publisher's Note: MDPI stays neutral with regard to jurisdictional claims in published maps and institutional affiliations.

Copyright: (c) 2021 by the authors. Licensee MDPI, Basel, Switzerland. This article is an open access article distributed under the terms and conditions of the Creative Commons Attribution (CC BY) license (https:// creativecommons.org/licenses/by/ $4.0 /)$.

\begin{abstract}
The objective of this study was to evaluate serum, hair, and urinary trace element and mineral content in normal-weight and obese women in relation to metabolic risk factors. A total of 80 women aged 30-70 y.o. were enrolled in the obese group $(n=40)$ and normal-weight group $(n=40)$. Serum, hair, and urinary trace element and mineral levels were assessed using inductively coupled plasma spectrometry. Body fat percentage was evaluated using bioimpedance. Obese subjects were characterized by significantly higher body fat percentage, blood pressure, serum triglyceride concentration, and insulin resistance. Serum $\mathrm{Ca}, \mathrm{Fe}, \mathrm{Mg}$, Se, V, Zn levels, hair Fe, Mg, V content, and urinary Se and $\mathrm{V}$ concentrations were found to be lower in obese subjects as compared to lean controls. In turn, serum $\mathrm{Cu}$ and urinary Fe levels in obese women were characterized by a significant increase. In multiple regression models serum $\mathrm{Cu}, \mathrm{Se}$, and $\mathrm{Zn}$ levels were significantly associated with BMI even after adjustment for blood biochemistry, body composition, and blood pressure. Serum trace element and mineral levels also significantly contributed to group discrimination. These findings allow to propose that obesity-associated disturbances in trace element and mineral status may at least partially contribute to metabolic risk in obese subjects.
\end{abstract}

Keywords: obesity; metabolic syndrome; insulin resistance; copper; selenium

\section{Introduction}

Obesity is considered as a worldwide epidemic affecting $11 \%$ men and $15 \%$ women worldwide [1]. Due to the role of obesity as the key component of metabolic syndrome, it accounts for 2.8 million deaths worldwide [2].

Micronutrient deficiency is considered as one of the characteristic patterns in obesity due to increased consumption of refined foods [3]. Correspondingly, multiple studies demonstrated impaired iron [4], magnesium [5], and zinc [6] in obese subjects. However, data on the association of obesity and selenium are contradictory and/or insufficient [7]. In contrast, accumulating evidence demonstrate that obesity may be associated with copper accumulation [8]. However, multiple contradictions regarding the association between obesity and trace element status exist [9,10]. A significant proportion of contradictory results may be attributable to the use of various substrates and markers for assessment of trace element and mineral status. 
A number of studies have been aimed at the assessment of the relationship between trace elements and minerals in obesity and metabolic risk. Particularly, it has been demonstrated that certain patterns of hair trace element content may be characteristic for metabolically healthy obesity [11]. However, using urine for assessment of trace element status resulted in a distinct outcome [12]. We have also demonstrated that serum, hair, and dietary trace element levels are differentially associated with metabolic parameters in obese subjects [13]. However, the association between altered metabolic profile and mineral status is still contradictory.

Therefore, the objective of the study was to evaluate serum, hair, and urinary trace element and mineral content in normal-weight and obese women in relation to metabolic risk factors, as well as to estimate the contribution of trace elements in discrimination between the groups.

\section{Materials and Methods}

\subsection{Ethical Statement}

The study protocol has been approved by Ethics Committee, Poznan University of Medical Sciences (approval no. 1104/16 and no. 450/17) and fulfilled the requirements of The Declaration of Helsinki (1975 revision with amendments). The study is a part of a research which has been registered on ClinicalTrials.gov NCT03439540.

\subsection{Study Design}

Informed consent in writing has been obtained from each patient. Obesity was diagnosed on the basis of body mass index according to WHO criteria (BMI $\geq 30 \mathrm{~kg} / \mathrm{m}^{2}$ ). Patients were recruited to two groups: study group with obesity and control group with normal-weight. A total of 80 women aged 30-70 years-old (y.o.) were enrolled in the obese group $(n=40)$ and normal-weight group $(n=40)$.

Patients who met all of the following inclusion criteria were enrolled: written informed consent; women aged 18 years and more; adequate value of BMI index $\left(\geq 30 \mathrm{~kg} / \mathrm{m}^{2}\right.$ to the study group and $18.5-24.9 \mathrm{~kg} / \mathrm{m}^{2}$ to the control group), stable body weight one month prior to enrolment (acceptable deviation was $\pm 1 \mathrm{~kg}$ ). The exclusion criteria were the following: diabetes, secondary form of obesity, diseases of the gastrointestinal tract, hepatic cirrhosis, dyslipidemia, hypertension requiring the implementation or modification of pharmacological treatment in the last 3 months before the enrollment or during the intervention, use of any dietary supplements within the last month before enrolment or during the study, a clinically relevant acute or chronic inflammatory process in the respiratory, digestive or genitourinary tract or in the mouth, throat, paranasal sinuses or connective tissue disease, arthritis, smoking, alcohol abuse, drug use, pregnancy, lactation, hormone replacement therapy. Patients' age and sex were self-reported. Patients who met all inclusion criteria and did not present any of the exclusion criteria were included into the study. The occurrence of any of exclusion criterion during the study resulted in withdrawal of the patient from the trial.

\subsection{Bioimpedance}

Body composition analysis was determined using electrical bioimpedance InBody 370 device (InBody Bldg, Seoul, Korea), percentile fat mass (FAT\%) was performed.

\subsection{Anthropometric Measurements}

Anthropometric parameters and body composition analyses were performed in the conditions of metabolic laboratory in patients wearing light clothes without shoes, fasting, at morning, after night-long sleep. BMI was calculated as the body mass divided by the height squared $\left(\mathrm{kg} / \mathrm{m}^{2}\right)$. The waist circumference (WC) was measured to the nearest 0.5 $\mathrm{cm}$ in the horizontal plane midway between the lowest rib and the iliac crest at the end of normal expiration. 


\subsection{Blood Pressure Measurement}

Blood pressure measurements were performed using digital electronic tensiometer (model 705IT TM, Omron Corporation, Kyoto, Japan). Standard or large-size cuffs for adults were used. During the measurement patient was sitting in a chair for $>5 \mathrm{~min}$, feet on floor, back supported, after relaxation, with empty bladder. Three subsequent measurements were performed, and the mean was calculated. Heart rate (HR) was measured in the same conditions.

\subsection{Blood, Urine, and Hair Sampling}

Blood samples have been collected after all-night sleep, at the morning, fasting, at room temperature, without previous caffeine consumption. Before collection patient was lying supine in silence for $30 \mathrm{~min}$. Blood samples were collected from ulnar vein into serum separation tubes. After preparation serum samples have been frozen and secured in $-80^{\circ} \mathrm{C}$.

Urine samples were collected in the morning after overnight fasting using commerciallyavailable plastic Vacuette ${ }^{\circledR}$ Urine Collection Cups. Only the second portion of the first morning urine was collected and subsequently stored frozen at $-30^{\circ} \mathrm{C}$.

Hair samples were collected at the day of blood and urine sampling. Proximal parts (1-2 $\mathrm{cm}$, total weight of $0.1 \mathrm{~g}$ ) of occipital scalp hair strands were collected after washing hair using ethanol-precleaned stainless steel scissors. Hair samples were stored in a laboratory at room temperature until analysis.

\subsection{Biochemical Analysis}

Serum levels of lipids-including total cholesterol (TCH), high-density lipoprotein cholesterol (HDL), and triglycerides (TG) were assayed by routine enzymatic methods with a Dimension EXL with LM Integrated Chemistry System Analyzer. Low-density lipoprotein cholesterol (LDL) was calculated from Friedewald's formula. Glucose concentration was assessed by an enzymatic method with hexokinase, glucose HK gen.3 (GLUC.3), and insulin concentration was assessed by electrochemiluminescence immunoassay (Cobas analyzer). Homeostasis model assessment of insulin resistance (HOMA-R) was calculated based on fasting glucose concentration $(\mathrm{mg} / \mathrm{dL})$ and fasting insulin concentration $(\mathrm{mU} / \mathrm{mL})$ using the standard equation: (fasting plasma glucose/fasting plasma insulin)/405.

The accuracy and precision of the techniques used to assess all parameters were validated. Accuracy was assessed by means of the recovery value, which ranged between $95 \%$ and $109 \%$. The variability coefficient did not exceed $10 \%$.

\subsection{Hair, Serum, and Urine Sample Preparation}

The collected hair samples were washed with acetone and $18.2 \mathrm{M} \Omega \cdot \mathrm{cm}$ deionized water (Labconco Corp., Kansas City, MO, USA) with subsequent drying on air to a stable weight. Washed hair samples were subjected to microwave-assisted acid digestion in Berghof SpeedWave-4 DAP-40 system (Berghof Products + Instruments GmbH, 72800 Eningen, Germany) at microwave frequency, $2.46 \mathrm{GHz}$; power, $1450 \mathrm{~W}$. Briefly, $50 \mathrm{mg}$ dry hair samples were digested in Teflon tubes with $5 \mathrm{~mL}$ of concentrated $(65 \%)$ nitric acid (Sigma-Aldrich Co., St. Louis, MO, USA) for $20 \mathrm{~min}$ at $170-180^{\circ} \mathrm{C}$. After cooling the system, the samples were adjusted to a final volume of $15 \mathrm{~mL}$ with distilled deionized water.

In turn, serum and urine samples were diluted $1: 15$ with an acidified $(\mathrm{pH}=2.0)$ diluent containing $(v / v)$ 1-Butanol 1\% (Merck KGaA, Darmstadt, Germany), Triton X-100 0.1\% (Sigma-Aldrich, Co., St. Louis, MO USA), and $\mathrm{HNO}_{3}$ 0.07\% (Sigma-Aldrich, Co., St. Louis, $\mathrm{MO}, \mathrm{USA}$ ) in distilled deionized water.

\subsection{ICP-MS Analysis}

The analysis of calcium $(\mathrm{Ca})$, copper $(\mathrm{Cu})$, iron $(\mathrm{Fe})$, magnesium $(\mathrm{Mg})$, selenium $(\mathrm{Se})$, vanadium $(\mathrm{V})$, and zinc $(\mathrm{Zn})$ levels in the studied samples was performed using inductivelycoupled plasma mass-spectrometry (ICP-MS) at NexION 300D (PerkinElmer Inc., Shelton, 
CT, USA) equipped with a 7-port FAST valve and ESI SC-2 DX4 autosampler (Elemental Scientific Inc., Omaha, NE, USA). External calibration of the ICP-MS system was performed with $0.5,5,10$ and $50 \mu \mathrm{g} / \mathrm{L}$ solutions of the studied elements. Calibration solutions were prepared from the Universal Data Acquisition Standards Kit (PerkinElmer Inc., Shelton, CT, USA). Internal on-line standardization was performed using $10 \mu \mathrm{g} / \mathrm{L}$ solutions of yttrium89 and rhodium-103. The solutions were prepared from commercially available Yttrium (Y) and Rhodium (Rh) Pure Single-Element Standard (PerkinElmer Inc. Shelton, CT, USA) on a matrix containing 1-butanol 8\% (Merck KGaA, Gernsheim, Germany), Triton X-100 0.8\% (Sigma-Aldrich Co., St. Louis, MO, USA), tetramethylammonium hydroxide $0.02 \%$ (Alfa Aesar, Ward Hill, MA, USA) and ethylenediaminetetraacetic acid 0.02\% (Sigma-Aldrich Co., St. Louis, MO, USA). The results of serum analysis were expressed as $\mu \mathrm{g} / \mathrm{mL}$ for all elements except $\mathrm{V}(\mathrm{ng} / \mathrm{mL})$. Data on hair and urinary trace element and mineral content are provided for all elements as $\mu \mathrm{g} / \mathrm{g}$ and $\mu \mathrm{g} / \mathrm{mL}$, respectively.

\subsection{Laboratory Quality Control}

Laboratory quality control was performed using the reference materials of human hair (GBW09101, Shanghai Institute of Nuclear Research, Shanghai, China), plasma (ClinChek ${ }^{\circledR}$ Plasma Control, Levels I, II, Lot 1286), and urine (ClinChek ${ }^{\circledR}$ Urine Control, Levels I, II, Lot 1227). The recovery rates for reference materials of human hair, plasma, and urine were $91-107 \%, 93-105 \%$, and $91-108 \%$, respectively. In addition, sampling procedure purity was evaluated using blank samples of $18.2 \mathrm{M} \Omega \cdot \mathrm{cm}$ deionized water (Labconco Corp., Kansas City, MO, USA) that underwent all steps of sampling procedures and storage.

\subsection{Statistical Analysis}

The obtained data were processed Statistica 10.0 (Statsoft, OK, USA). Data distribution was evaluated using the Shapiro-Wilk test. Trace element and mineral levels were characterized by skewed distribution, thus being expressed as median and the respective interquartile range (IQR) boundaries. In turn, metabolic parameters followed Gaussian distribution and descriptive statistics included mean and the respective standard deviation. Group comparisons were performed using analysis of covariance (ANCOVA) adjusted for age, BMI, and metabolic parameters using Bonferroni post-hoc analysis. Data on trace element and mineral levels characterized by skewed distribution were subjected to logtransformation prior analysis. Correlation analysis was performed using Spearman rank correlation coefficient. Multiple linear regression analysis was performed in order to reveal independent association between BMI as a dependent variable and trace element and mineral levels in various biosamples as independent predictors with adjustment for metabolic parameters (routine predictors). Model 1 incorporated only metabolic parameters, blood pressure, and age as independent variables, whereas Models 2, 3, and 4 also included data on serum, hair, and urinary trace element and mineral levels, respectively. Discriminant analysis was performed in order to assess significant discrimination between the study groups based on metabolic parameters and trace element content in biosamples with evaluation of significance of the distance between group vectors. The level of significance was set as $p<0.05$ for all statistical methods.

\section{Results}

The obtained data demonstrate that obese subjects were characterized by $63 \%$ and $60 \%$ higher body weight and BMI values as compared to lean controls, respectively (Table 1). At the same time, no significant differences in age and height were revealed. SBP and DBP in obese examinees exceeded the control values by $11 \%$ and $13 \%$, whereas heart rate did not differ significantly between the groups. 
Table 1. Anthropometric and metabolic parameters in subjects with normal weight and obesity.

\begin{tabular}{cccc}
\hline Parameter & Control $(\mathbf{n}=\mathbf{4 0})$ & Obese $(\mathbf{n}=\mathbf{4 0})$ & $p$ Value \\
\hline Age, y.o. & $52.5 \pm 11.8$ & $51.4 \pm 12.2$ & 0.603 \\
Height, cm & $162.2 \pm 6.6$ & $163.6 \pm 6.9$ & 0.209 \\
Body mass, $\mathrm{kg}$ & $59.9 \pm 6.2$ & $97.4 \pm 16.8$ & $<0.001^{*}$ \\
BMI, $\mathrm{kg} / \mathrm{m}^{2}$ & $22.7 \pm 1.4$ & $36.4 \pm 5$ & $<0.001^{*}$ \\
BF, \% & $30.4 \pm 5.4$ & $46.3 \pm 5.4$ & $<0.001^{*}$ \\
SBP, $\mathrm{mmHg}$ & $128.4 \pm 18.5$ & $142.8 \pm 18.6$ & $<0.001^{*}$ \\
DBP, $\mathrm{mmHg}$ & $76.3 \pm 11.5$ & $85.9 \pm 10.7$ & $<0.001^{*}$ \\
HR, bpm & $77.7 \pm 13.8$ & $80.2 \pm 11.9$ & 0.381 \\
TC, mg/dL & $213.3 \pm 43.4$ & $184 \pm 44.2$ & $<0.001^{*}$ \\
HDL-C, mg/dL & $77.7 \pm 18.5$ & $46 \pm 17.7$ & $0.001^{*}$ \\
LDL-C, mg/dL & $115.2 \pm 40.6$ & $120.8 \pm 45.6$ & $0.003^{*}$ \\
TG, mg/dL & $110.3 \pm 54.3$ & $143 \pm 69.3$ & 0.622 \\
FPG, mg/dL & $90.3 \pm 14.9$ & $88.4 \pm 25.9$ & $0.012^{*}$ \\
Insulin, $\mu$ U /mL & $11.4 \pm 8.5$ & $16 \pm 11.4$ & $0.023^{*}$ \\
HOMA-IR & $2.5 \pm 2$ & $3.7 \pm 3.4$ &
\end{tabular}

Data expressed as Mean $\pm \mathrm{SD} ;{ }^{*}$ - significant group difference at $p<0.05$ according to ANCOVA with Bonferroni adjustment; $\mathrm{BMI}$ - body mass index, $\mathrm{BF}$ - body fat percentage, SBP — systolic blood pressure, DBP-diastolic blood pressure, HR-heart rate, TC - total cholesterol, HDL-C - high density lipoprotein cholesterol, LDL-Clow density lipoprotein cholesterol, TG—triglycerides, HOMA-IR-Homeostatic Measurement AssessmentInsulin Resistance.

Obesity was associated with alteration of metabolic profile in the studied group of subjects (Table 1). Surprisingly, serum total cholesterol levels were $14 \%$ lower in obese patients when compared to the control subjects. At the same time, serum HDL-C levels were found to be $41 \%$ lower whereas LDL-C concentration tended to increase in obesity. Moreover, serum TG levels in the examined obese subjects were $30 \%$ higher than those in control examinees, altogether being indicative of atherogenic lipid profile.

The analysis of serum glucose concentration failed to reveal any group difference in serum glucose in the studied sample of obese patients, whereas serum insulin levels were found to be $40 \%$ higher. Correspondingly, $48 \%$ higher HOMA-IR values in obese examinees are indicative of insulin resistance without manifest hyperglycemia.

Obesity was associated with altered trace elements in serum, hair, and urine (Table 2). Serum Ca, Fe, Mg, Se, V, and Zn levels were found to be $28 \%, 27 \%, 14 \%, 37 \%, 42 \%$, and $8 \%$ lower in obese subjects as compared to lean controls. At the same time, serum Cu levels in obese examinees significantly exceeded the respective control values by $3 \%$.

Hair analysis revealed 35\% and $41 \%$ lower hair Fe and $\mathrm{Mg}$ content in obese examinees as compared to the control values, respectively. Hair V levels were found to be twofold lower than those in the lean controls. In turn, the observed 15\% and 19\% decrease in hair Se and $\mathrm{Zn}$ content in the obese group, these differences were only nearly significant $(p<0.1)$.

Urinary trace element and mineral levels were also affected in obesity. Particularly, urinary Se and V concentrations were $31 \%$ and $41 \%$ lower when compared to normalweight controls, respectively. In turn, urinary Fe levels in obese patients were more than two-fold higher than those in lean controls. 
Table 2. Serum, hair, and urinary trace element and mineral levels in normal weight and obese subjects.

\begin{tabular}{|c|c|c|c|}
\hline Element & Control $(n=40)$ & Obese $(n=40)$ & $p$ Value \\
\hline \multicolumn{4}{|c|}{ Serum } \\
\hline $\mathrm{Ca}, \mu \mathrm{g} / \mathrm{mL}$ & $101.8(97.9-106.6)$ & $74.2(70.7-78.6)$ & $<0.001 *$ \\
\hline $\mathrm{Cu}, \mu \mathrm{g} / \mathrm{mL}$ & $1.136(0.938-1.315)$ & $1.170(1.07-1.290)$ & 0.018 * \\
\hline $\mathrm{Fe}, \mu \mathrm{g} / \mathrm{mL}$ & $1.243(0.923-1.505)$ & $0.910(0.736-1.150)$ & $0.001 *$ \\
\hline $\mathrm{Mg}, \mu \mathrm{g} / \mathrm{mL}$ & $22.7(21.3-23.3)$ & $19.5(17.9-20.7)$ & $<0.001$ * \\
\hline $\mathrm{Se}, \mu \mathrm{g} / \mathrm{mL}$ & $0.106(0.096-0.116)$ & $0.067(0.061-0.078)$ & $<0.001 *$ \\
\hline $\mathrm{V}, \mathrm{ng} / \mathrm{mL}$ & $5.316(4.412-5.766)$ & $3.1(2.7-3.2)$ & $<0.001$ * \\
\hline $\mathrm{Zn}, \mu \mathrm{g} / \mathrm{mL}$ & $0.88(0.805-0.947)$ & $0.814(0.762-0.87)$ & $0.001 *$ \\
\hline \multicolumn{4}{|c|}{ Hair } \\
\hline $\mathrm{Ca}, \mu \mathrm{g} / \mathrm{g}$ & $1406.3(773.6-2755.9)$ & 1738 (650-2929) & 0.699 \\
\hline $\mathrm{Cu}, \mu \mathrm{g} / \mathrm{g}$ & $14.456(10.705-25.87)$ & 13.5 (12.03-18.57) & 0.936 \\
\hline $\mathrm{Fe}, \mu \mathrm{g} / \mathrm{g}$ & $14.381(9.183-24.417)$ & $9.3(6.75-13.58)$ & $0.008 *$ \\
\hline $\mathrm{Mg}, \mu \mathrm{g} / \mathrm{g}$ & $152.3(67.3-265.5)$ & $89.7(53.4-154)$ & $0.017^{*}$ \\
\hline $\mathrm{Se}, \mu \mathrm{g} / \mathrm{g}$ & $0.391(0.331-0.461)$ & $0.332(0.278-0.42)$ & 0.074 \\
\hline $\mathrm{V}, \mu \mathrm{g} / \mathrm{g}$ & $0.014(0.01-0.034)$ & $0.007(0.004-0.011)$ & $<0.001$ * \\
\hline $\mathrm{Zn}, \mu \mathrm{g} / \mathrm{g}$ & 198.7 (160.3-227.5) & $160(132-188)$ & 0.062 \\
\hline \multicolumn{4}{|c|}{ Urine } \\
\hline $\mathrm{Ca}, \mu \mathrm{g} / \mathrm{mL}$ & 97.7 (53.5-154.5) & $96.2(46.3-157)$ & 0.932 \\
\hline $\mathrm{Cu}, \mu \mathrm{g} / \mathrm{mL}$ & $0.011(0.008-0.017)$ & $0.011(0.008-0.016)$ & 0.808 \\
\hline $\mathrm{Fe}, \mu \mathrm{g} / \mathrm{mL}$ & $0.022(0.015-0.041)$ & $0.046(0.018-0.213)$ & $0.012 *$ \\
\hline $\mathrm{Mg}, \mu \mathrm{g} / \mathrm{mL}$ & $77.7(50.7-128.8)$ & $67.7(47.7-98.3)$ & 0.142 \\
\hline Se, $\mu \mathrm{g} / \mathrm{mL}$ & $0.026(0.015-0.041)$ & $0.018(0.01-0.026)$ & $0.016^{*}$ \\
\hline $\mathrm{V}, \mathrm{ng} / \mathrm{mL}$ & $0.068(0.041-0.157)$ & $0.040(0.005-0.09)$ & $0.006^{*}$ \\
\hline $\mathrm{Zn}, \mu \mathrm{g} / \mathrm{mL}$ & $0.284(0.183-0.465)$ & $0.282(0.177-0.431)$ & 0.400 \\
\hline
\end{tabular}

Data expressed as Median and the respective IQR boundaries; *- significant group difference at $p<0.05$ according to ANCOVA with Bonferroni adjustment.

Correlation analysis demonstrated that trace element and mineral levels in the studied samples were significantly associated with anthropometric and metabolic parameters (Table 3). Particularly, BMI values were characterized by a significant inverse correlation with serum $\mathrm{Ca}, \mathrm{Fe}, \mathrm{Mg}, \mathrm{V}, \mathrm{Zn}$ levels, hair $\mathrm{Mg}$ and V content, as well as urinary Se concentrations. Systolic blood pressure was negatively associated with serum $\mathrm{Ca}, \mathrm{Mg}$, Se, V, and $\mathrm{Zn}$ levels, as well as hair $\mathrm{Mg}$ content. DBP inversely correlated with serum $\mathrm{Ca}, \mathrm{Mg}, \mathrm{Se}, \mathrm{V}$, and $\mathrm{Zn}$ concentrations, whereas serum $\mathrm{Cu}$ level was positively associated with this parameter. Serum HDL-C levels positively correlated with serum $\mathrm{Ca}, \mathrm{Fe}, \mathrm{Mg}$, Se, V, Zn, hair V, and urinary Se concentration. Similar, although less pronounced associations were revealed in the case of serum TC. In turn, serum $\mathrm{Ca}, \mathrm{Mg}$, Se, V, and $\mathrm{Zn}$ were inversely associated with TG levels. Certain associations were revealed between trace element and mineral levels and markers of carbohydrate metabolism. In turn, circulating insulin levels were characterized by inverse association with serum $\mathrm{Ca}, \mathrm{Fe}, \mathrm{Mg}$, $\mathrm{Se}, \mathrm{Zn}$, as well as urinary $\mathrm{Mg}$ and Se concentration. At the same time, serum $\mathrm{Cu}$ level positively correlated with insulin levels. Correspondingly, serum $\mathrm{Cu}$ concentrations directly correlated with HOMA-IR values, whereas serum $\mathrm{Mg}$ and $\mathrm{Zn}$, as well as urinary $\mathrm{Mg}$ were inversely associated with the latter. Heart rate and fasting plasma glucose were slightly associated with trace element and mineral profile. Specifically, heart rate was characterized by weak inverse correlation with serum $\mathrm{Zn}(\mathrm{r}=-0.203)$ and urinary Se $(\mathrm{r}=-0.188)$ levels, whereas serum glucose negatively correlated only with hair Se content $(r=-0.185)$. 
Table 3. Correlation between trace element and mineral levels in the studied biosamples and BMI, blood pressure, and metabolic parameters in the studied cohort.

\begin{tabular}{|c|c|c|c|c|c|c|c|c|c|}
\hline Element & $\begin{array}{c}\text { BMI, } \\
\mathrm{kg} / \mathrm{m}^{2}\end{array}$ & $\mathrm{BF}, \%$ & $\begin{array}{c}\text { SBP, } \\
\mathrm{mmHg}\end{array}$ & $\begin{array}{c}\text { DBP, } \\
\mathrm{mmHg}\end{array}$ & $\begin{array}{c}\mathrm{TC} \\
\mathrm{mg} / \mathrm{dL}\end{array}$ & $\begin{array}{l}\text { HDL-C, } \\
\mathrm{mg} / \mathrm{dL}\end{array}$ & $\begin{array}{c}\text { TG, } \\
\mathrm{mg} / \mathrm{dL}\end{array}$ & $\begin{array}{l}\text { insulin, } \\
\mu \mathrm{U} / \mathrm{mL}\end{array}$ & $\begin{array}{c}\text { HOMA- } \\
\text { IR }\end{array}$ \\
\hline Serum Ca & $-0.776^{*}$ & $-0.748^{*}$ & $-0.343 *$ & $-0.369 *$ & 0.339 * & 0.605 * & $-0.245^{*}$ & $-0.174 *$ & -0.151 \\
\hline Serum $\mathrm{Cu}$ & 0.293 * & $0.245^{*}$ & 0.156 & 0.195 * & -0.045 & -0.153 & 0.097 & $0.364^{*}$ & $0.302 *$ \\
\hline Serum Fe & $-0.193 *$ & $-0.260^{*}$ & -0.167 & -0.138 & 0.141 & 0.191 * & -0.027 & $-0.174 *$ & -0.143 \\
\hline $\begin{array}{c}\text { Serum } \\
\mathrm{Mg}\end{array}$ & $-0.592 *$ & $-0.560^{*}$ & $-0.321 *$ & $-0.323 *$ & 0.205 * & 0.477 * & $-0.269 *$ & $-0.214^{*}$ & -0.186 * \\
\hline Serum Se & $-0.686^{*}$ & $-0.610^{*}$ & $-0.183 *$ & $-0.248 *$ & $0.376^{*}$ & 0.569 * & $-0.210 *$ & $-0.181^{*}$ & -0.146 \\
\hline Serum V & $-0.544^{*}$ & $-0.553^{*}$ & $-0.219 *$ & $-0.264 *$ & $0.272 *$ & $0.445^{*}$ & $-0.177^{*}$ & -0.097 & -0.089 \\
\hline Serum Zn & $-0.261^{*}$ & $-0.218^{*}$ & $-0.250 *$ & $-0.206^{*}$ & 0.250 * & $0.222 *$ & $-0.219 *$ & $-0.274^{*}$ & -0.224 * \\
\hline Hair Mg & $-0.228^{*}$ & $-0.204^{*}$ & $-0.208^{*}$ & -0.151 & 0.075 & 0.160 & -0.115 & -0.098 & -0.084 \\
\hline Hair Se & -0.130 & -0.103 & -0.031 & -0.022 & 0.141 & 0.015 & 0.109 & -0.019 & -0.058 \\
\hline Hair V & $-0.235^{*}$ & $-0.194^{*}$ & -0.027 & -0.065 & 0.059 & 0.204 * & -0.084 & 0.166 & 0.146 \\
\hline Urine $\mathrm{Mg}$ & -0.132 & -0.120 & -0.144 & -0.142 & 0.080 & 0.157 & -0.062 & $-0.212 *$ & $-0.215^{*}$ \\
\hline Urine Se & $-0.239 *$ & $-0.274^{*}$ & -0.106 & -0.126 & 0.223 * & 0.239 * & 0.030 & $-0.185^{*}$ & -0.157 \\
\hline
\end{tabular}

Data expressed as Spearman rank correlation coefficient $(\mathrm{r}) ;{ }^{*}$ — significant correlation at $p<0.05$; BMI—body mass index, SBP—systolic blood pressure, DBP—diastolic blood pressure, HR - heart rate, TC — total cholesterol, HDL-C—high density lipoprotein cholesterol, LDL-C-low density lipoprotein cholesterol, TG—-triglycerides, HOMA-IR-Homeostatic Measurement Assessment-Insulin Resistance.

In view of the observed correlation between mineral levels, metabolic and anthropometric parameters, multiple linear regression analysis was performed in order to reveal the independent association between trace element and mineral levels and BMI values after adjustment for metabolic markers (Table 4). Model 1 incorporating only metabolic parameters and blood pressure values accounted for 53\% variability of BMI. HDL-C and SBP values were considered as negative and positive predictors of BMI. Including serum trace element and mineral levels into the model (Model 2) significantly increased predictive value of the model by more than $18 \%$ (from $53.0 \%$ to $71.8 \%$ ). Serum $\mathrm{Ca}$, Se, and $\mathrm{Zn}$ levels were found to be inversely associated with BMI values, whereas serum $\mathrm{Cu}$ concentration was directly associated with higher BMI. Models 3 and 4 incorporating hair and urinary trace element and mineral levels did not improve predictive ability of the baseline model (Model 1). None of hair or urinary element levels were found to be significantly associated with BMI.

Given the tight independent association between serum trace element and mineral levels with BMI, the most effective model (Model 2) was also adjusted for percentage body fat assessed by bioimpedance analysis. The obtained data demonstrate that the resulting model accounts for nearly $80 \%$ of BMI variability (Multiple $\mathrm{R}=0.909$; Multiple $\mathrm{R}^{2}=0.827$; Adjusted $\mathrm{R}^{2}=0.799 ; p$ for a model $\left.<0.001\right)$. It is clear that body fat percentage was considered as the most significant predictor for BMI $(\beta=0.455 ; p<0.001)$. Serum $\mathrm{Cu}(\beta=0.110 ; p=0.016)$, Se $(\beta=-0.188 ; p=0.009)$, and $\mathrm{Zn}(\beta=-0.118 ; p=0.018)$ levels remained significantly associated with BMI even after adjustment for body composition. In addition, serum TG levels ( $\beta=0.107 ; p=0.044)$ and SBP $(\beta=0.149 ; p=0.014)$ values were found to be directly associated with BMI values.

Discriminant analysis (Figure 1) was performed in order to reveal the contribution of the particular variables into discrimination between the groups. Although the model incorporating metabolic parameters and blood pressure values revealed significant distance between the groups $\left(\mathrm{MD}^{2}=7.20 ; p<0.001\right)$, complete discrimination was not observed (Figure 1). TC, HDL-C, LDL-C (all $p<0.001)$, SBP $(p=0.004)$, and circulating insulin $(p=0.041)$ values were found to contribute significantly into the model. Inclusion of serum trace element and mineral levels, characterized by the most significant association with BMI, significantly increased the distance between the groups $\left(\mathrm{MD}^{2}=36.78 ; p<0.001\right)$ resulting in complete discrimination. Serum Ca, V, Zn (all $p<0.001), \mathrm{Cu}(p=0.002)$, Se $(p=0.011)$, and $\mathrm{Mg}(p=0.036)$ levels contributed significantly to group discrimination along with HDL-C $(p<0.001)$ and SBP $(p=0.031)$ values. 
Table 4. Multiple regression analysis of the association between trace element and mineral levels with BMI after adjustment for multiple clinical and laboratory markers.

\begin{tabular}{|c|c|c|c|c|c|c|c|c|}
\hline \multirow{2}{*}{ Parameter } & \multicolumn{2}{|c|}{ Model 1} & \multicolumn{2}{|c|}{ Model 2 (Serum) } & \multicolumn{2}{|c|}{ Model 3 (Hair) } & \multicolumn{2}{|c|}{ Model 4 (Urine) } \\
\hline & $\beta$ & $p$ & $\beta$ & $p$ & $\beta$ & $p$ & $\beta$ & $p$ \\
\hline $\mathrm{FPG}, \mathrm{mg} / \mathrm{dL}$ & -0.026 & 0.824 & -0.009 & 0.924 & -0.090 & 0.473 & 0.003 & 0.984 \\
\hline $\mathrm{TC}, \mathrm{mg} / \mathrm{dL}$ & -0.149 & 0.090 & 0.012 & 0.869 & -0.132 & 0.163 & -0.090 & 0.376 \\
\hline HDL-C mg/dL & -0.529 & $<0.001 *$ & -0.164 & $0.029 *$ & -0.476 & $<0.001$ * & -0.540 & $<0.001$ * \\
\hline LDL-C, mg/dL & 0.040 & 0.631 & -0.052 & 0.446 & 0.040 & 0.658 & 0.053 & 0.562 \\
\hline HOMA-IR & 0.323 & 0.279 & 0.097 & 0.692 & 0.384 & 0.217 & 0.348 & 0.274 \\
\hline $\mathrm{TG}, \mathrm{mg} / \mathrm{dL}$ & 0.071 & 0.380 & 0.096 & 0.139 & 0.087 & 0.290 & 0.047 & 0.613 \\
\hline Insulin, $\mu \mathrm{U} / \mathrm{mL}$ & -0.222 & 0.411 & 0.003 & 0.989 & -0.241 & 0.395 & -0.242 & 0.406 \\
\hline Age, y.o. & -0.033 & 0.638 & 0.011 & 0.841 & -0.011 & 0.884 & -0.032 & 0.688 \\
\hline $\mathrm{SBP}, \mathrm{mmHg}$ & 0.212 & 0.024 * & 0.155 & $0.041 *$ & 0.170 & 0.083 & 0.250 & $0.016^{*}$ \\
\hline $\mathrm{DBP}, \mathrm{mmHg}$ & 0.159 & 0.085 & 0.021 & 0.773 & 0.159 & 0.090 & 0.135 & 0.186 \\
\hline $\mathrm{HR}, \mathrm{bpm}$ & 0.014 & 0.849 & 0.055 & 0.338 & 0.016 & 0.830 & 0.019 & 0.818 \\
\hline $\mathrm{Ca}, \mu \mathrm{g} / \mathrm{mL}$ & - & - & -0.391 & $<0.001 *$ & -0.001 & 0.996 & 0.015 & 0.880 \\
\hline $\mathrm{Cu}, \mu \mathrm{g} / \mathrm{mL}$ & - & - & 0.179 & $0.001 *$ & 0.011 & 0.867 & 0.035 & 0.689 \\
\hline $\mathrm{Fe}, \mu \mathrm{g} / \mathrm{mL}$ & - & - & 0.037 & 0.481 & -0.062 & 0.357 & 0.030 & 0.701 \\
\hline $\mathrm{Mg}, \mu \mathrm{g} / \mathrm{mL}$ & - & - & -0.021 & 0.777 & -0.093 & 0.296 & -0.211 & 0.083 \\
\hline Se, $\mu \mathrm{g} / \mathrm{mL}$ & - & - & -0.230 & $0.009 *$ & -0.127 & 0.075 & 0.065 & 0.412 \\
\hline $\mathrm{V}, \mathrm{ng} / \mathrm{mL}$ & - & - & -0.103 & 0.129 & -0.111 & 0.091 & 0.168 & 0.147 \\
\hline $\mathrm{Zn}, \mu \mathrm{g} / \mathrm{mL}$ & - & - & -0.198 & $0.001 *$ & -0.002 & 0.974 & 0.035 & 0.755 \\
\hline Multiple R & \multicolumn{2}{|c|}{0.755} & \multicolumn{2}{|c|}{0.871} & \multicolumn{2}{|c|}{0.777} & \multicolumn{2}{|c|}{0.761} \\
\hline Multiple $\mathrm{R}^{2}$ & \multicolumn{2}{|c|}{0.570} & \multicolumn{2}{|c|}{0.759} & \multicolumn{2}{|c|}{0.603} & \multicolumn{2}{|c|}{0.579} \\
\hline Adjusted $\mathrm{R}^{2}$ & \multicolumn{2}{|c|}{0.530} & \multicolumn{2}{|c|}{0.718} & \multicolumn{2}{|c|}{0.536} & \multicolumn{2}{|c|}{0.500} \\
\hline$p$ for a model & \multicolumn{2}{|c|}{$<0.001$ * } & \multicolumn{2}{|c|}{$<0.001 *$} & \multicolumn{2}{|c|}{$<0.001 *$} & \multicolumn{2}{|c|}{$<0.001 *$} \\
\hline
\end{tabular}

Data expressed as regression coefficient $(\beta)$ and the respective $p$ values; ${ }^{*}$-association is significant at $p<0.05$; BMI—body mass index, SBPsystolic blood pressure, DBP-diastolic blood pressure, HR - heart rate, TC — total cholesterol, HDL-C — high density lipoprotein cholesterol, LDL-C-low density lipoprotein cholesterol, TG—triglycerides, HOMA-IR-Homeostatic Measurement Assessment-Insulin Resistance.
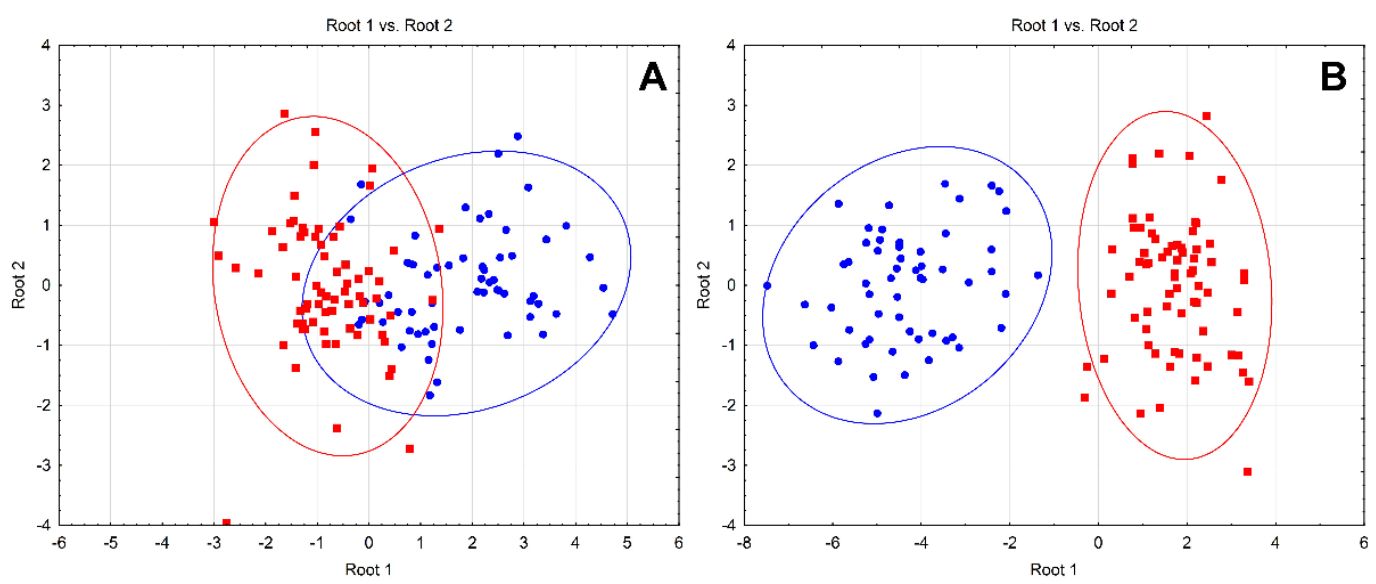

Figure 1. Discriminant analysis score plot of normal body weight (blue) and obesity (red) based on the patterns of metabolic parameters and blood pressure (A) or serum trace elements, metabolic parameters, and blood pressure (B).

\section{Discussion}

The obtained data clearly demonstrate that obese patients are characterized by altered trace element and mineral levels in the studied biosamples.

The obtained data clearly demonstrate altered iron status in obese examinees that may occur due to chronic inflammatory response in obesity with subsequent hepcidin overproduction [14]. The results of meta-analysis involving data from 13,393 overweight/obese and 26,621 normal weight subjects revealed significantly lower serum Fe levels in obesity [4]. At the same time, urinary iron excretion was found to be more than twofold higher 
in obese subjects when compared to lean controls, being indicative of obesity-associated oxidative stress [15]. Altered serum Fe levels were also inversely associated with circulating insulin levels as earlier demonstrated [3].

The observed increase in serum $\mathrm{Cu}$ levels in obese subjects corroborates the findings of the most recent meta-analysis demonstrating a positive association between increased serum $\mathrm{Cu}$ and obesity [8]. Moreover, a detailed study demonstrated that increased serum and adipose tissue $\mathrm{Cu}$ and cuproprotein levels are associated with leptin and insulin levels [16]. These findings are generally in agreement with the results of our previous experimental study demonstrating the potentiating effect of $\mathrm{Cu}$ intake on diet-induced obesity and adipose tissue hypertrophy [17]. Further analysis demonstrated tight association between high $\mathrm{Cu}$ levels and metabolic risk markers being in agreement with the observation of direct relationship between serum $\mathrm{Cu}$ and insulin resistance in prediabetic and diabetic postmenopausal women [18]. Positive association between $\mathrm{Cu}$ status and atherogenic lipid profile may underlie increased risk of atherosclerosis [19] and be mediated through the impact of $\mathrm{Cu}$ on lipid metabolism [20]. High serum $\mathrm{Cu}$ levels were also found to be associated with increased blood pressure [21], although the existing data are rather contradictory [22].

Se levels in the studied biosamples were found to be inversely associated with obesity that may occur due to the role of selenium and adipose tissue-resident selenoproteins in adipocyte physiology when both increased and decreased selenoprotein expression may result in adipocyte dysfunction [17]. The observed serum Se levels in obese subjects were also far lower than the reference ranges of $90-100 \mu \mathrm{g} / 1$ required for normal selenoprotein function [23]. Similar association was observed between Se status and diabetes [24] arising from the role of Se-dependent redox regulation of insulin signal transduction [25]. At the same time, hair Se levels were found to be inversely associated with HOMA-IR values in obese subjects [26]. The findings of increased endothelial dysfunction, vascular oxidative stress, and impaired NO-mediated vascular reactivity [27] may underlie the observed inverse association between Se status and blood pressure.

Zinc status was found to be inversely associated with anthropometric parameters including body composition and metabolic risk factors. This observation corresponds to the earlier studies summarized in a recent meta-analysis demonstrating low serum $\mathrm{Zn}$ levels in obese children and adults [6]. Our previous study also revealed a significant reduction in serum, hair, and urinary $\mathrm{Zn}$ levels in obesity [28]. Earlier, we also demonstrated a significant inverse association between serum $\mathrm{Zn}$, insulin, and total cholesterol levels [29], altogether corresponding to the role of $\mathrm{Zn}$ and $\mathrm{Zn}$-containing metalloproteins like $\mathrm{Zn}-\alpha 2$ glycoprotein in adipose tissue functioning, insulin signaling, and lipid metabolism [30]. Correspondingly, Zn supplementation was shown to improve body weight, insulin signaling, and systemic inflammation in obese individuals [31]. Inverse association between $\mathrm{Zn}$ status and blood pressure may be at least partially attributable to the newly demonstrated role of $\mathrm{Zn}$ deficiency in increasing renal sodium reabsorption [32].

Vanadium is known to play a significant role in insulin signaling though negative modulation of PTP1B and PTEN activity and stimulating downstream insulin signaling [33]. At the same time, our previous experimental [34] and human [28] studies demonstrated an inverse association between $\mathrm{V}$ levels and obesity. Correspondingly, V supplementation was shown to modulate adipogenesis [35], thus being indicative of its potential antiobesity effects [36].

The obtained data are generally in agreement with the previous studies demonstrating an association between dietary Ca deficiency and obesity [37]. Correspondingly, Ca supplementation was shown to reduce body weight as demonstrated by meta-analysis including data from 4733 participants [38]. The protective role of adequate calcium supply in obesity may be mediated by its impact on adipogenesis, thermogenesis, lipid metabolism, and gut microbiota [39]. Moreover, calcium may up-regulate the insulin signaling pathway, thus reducing insulin resistance in obesity [40]. 
The results of meta-analysis also demonstrate high rate of $\mathrm{Mg}$ deficiency in patients with obesity [41]. Mg deficiency was also found to be associated with insulin resistance in obesity [42] due to modulation of insulin receptor phosphorylation as well as insulin secretion [43]. Particularly, increased dietary Mg intake was associated with lower BMI and glucose levels [44]. Serum Mg levels is tightly associated with metabolic risk factors in obesity [45]. The role of $\mathrm{Mg}$ in modulating blood pressure may be mediated by the impact of $\mathrm{Mg}$ on cardiac output [46].

However, the revealed associations were sample-dependent, being observed predominantly in serum. Although findings on hair and urinary mineral content are generally in line with the patterns observed in serum, only serum trace element and mineral levels significantly correlated with metabolic parameters, being in agreement with the role of serum as the most reliable marker for trace element status assessment [47]. Mechanistically, more tight association between serum elements and metabolic parameters also assessed in serum may be at least partially mediated by the same matrix effects including dilution. In addition, the studied parameters in serum are subjected to homeostatic regulation, whereas urine and especially hair mineral levels are more variable. Our previous study also demonstrated a tight interrelation between serum $\mathrm{Zn}, \mathrm{Cr}$, and V levels and BMI, whereas in hair, only Se content was independently associated with BMI [28]. Serum mineral levels were also associated with more metabolic parameters (TG, TC, and HDL) than hair content (HDL, TG) [13]. Błażewicz et al. (2013) also observed more correlations between plasma/whole blood metal levels and BMI in children than in the case of urine [9].

This study has some limitations which have to be pointed out. The greatest limitation of the study is the relatively small number of patients in both groups. This was mainly due to rigorous inclusion and exclusion criteria, which allowed us to include a homogenous population of women not encumbered by states which could have affected the quality of the results. It is also notable that urinary trace element levels were not adjusted for creatinine, which could significantly reduce the variability of metal excretion data. Furthermore, in the present study, we did not determine nutritional factors and environmental factors that may affect the concentrations of elements in the analyzed samples.

\section{Conclusions}

The obtained data demonstrate that reduced $\mathrm{Ca}, \mathrm{Fe}, \mathrm{Mg}$, Se, $\mathrm{V}$, and $\mathrm{Zn}$, as well as increased $\mathrm{Cu}$ levels are independently associated with obesity, being also characterized by a significant relationship with insulin resistance, atherogenic lipid profile, and increased blood pressure. These findings allow to propose that obesity-associated disturbances in trace element and mineral status may at least partially contribute to metabolic risk in obese subjects. However, longitudinal studies are required to clarify the causal relationship between altered mineral status and metabolic risk on obesity.

Author Contributions: Conceptualization, A.A.T. and J.S.; methodology, A.V.S., M.G.S. and P.B.; software, A.A.T.; validation, M.G.S. and J.S.; formal analysis, A.A.T., D.S. and K.S.; investigation, A.A.T., P.B., D.S., K.S., A.V.S., M.G.S. and J.S.; resources, A.V.S., M.G.S., P.B. and J.S.; data curation, A.A.T., D.S. and K.S.; visualization, J.A.; writing-original draft preparation, A.A.T., D.S., K.S. and M.G.S.; writing—review and editing, P.B., A.V.S., J.A. and J.S.; supervision, A.A.T., P.B., A.V.S. and J.S.; project administration, J.S.; funding acquisition, A.A.T. All authors have read and agreed to the published version of the manuscript.

Funding: The study was performed with the support of the Russian Ministry of Science and Higher Education, Project № 0856-2020-0008.

Institutional Review Board Statement: The study was conducted according to the guidelines of the Declaration of Helsinki, and approved by the Ethics Committee of Poznan University of Medical Sciences (no. 1104/16 and no. 450/17).

Informed Consent Statement: Informed consent was obtained from all subjects involved in the study.

Conflicts of Interest: The authors declare no conflict of interest. 


\section{References}

1. Arroyo-Johnson, C.; Mincey, K.D. Obesity Epidemiology Worldwide. Gastroenterol. Clin. N. Am. 2016, 45, 571-579. [CrossRef]

2. WHO. Available online: https:/ / www.who.int/features/factfiles/obesity/en/ (accessed on 15 March 2021).

3. García, O.P.; Long, K.Z.; Rosado, J.L. Impact of micronutrient deficiencies on obesity. Nutr. Rev. 2009, 67, 559-572. [CrossRef] [PubMed]

4. Zhao, L.; Zhang, X.; Shen, Y.; Fang, X.; Wang, Y.; Wang, F. Obesity and iron deficiency: A quantitative meta-analysis. Obes. Rev. 2015, 16, 1081-1093. [CrossRef]

5. Sarrafzadegan, N.; Khosravi-Boroujeni, H.; Lotfizadeh, M.; Pourmogaddas, A.; Salehi-Abargouei, A. Magnesium status and the metabolic syndrome: A systematic review and meta-analysis. Nutrients 2016, 32, 409-417. [CrossRef] [PubMed]

6. Gu, K.; Xiang, W.; Zhang, Y.; Sun, K.; Jiang, X. The association between serum zinc level and overweight/obesity: A meta-analysis. Eur. J. Nutr. 2019, 58, 2971-2982. [CrossRef] [PubMed]

7. Tinkov, A.A.; Ajsuvakova, O.P.; Filippini, T.; Zhou, J.-C.; Lei, X.G.; Gatiatulina, E.R.; Michalke, B.; Skalnaya, M.G.; Vinceti, M.; Aschner, M.; et al. Selenium and Selenoproteins in Adipose Tissue Physiology and Obesity. Biomolecules 2020, 10, 658. [CrossRef] [PubMed]

8. Gu, K.; Li, X.; Xiang, W.; Jiang, X. The Relationship Between Serum Copper and Overweight/Obesity: A Meta-analysis. Biol. Trace Elem. Res. 2019, 194, 336-347. [CrossRef]

9. Błażewicz, A.; Klatka, M.; Astel, A.; Partyka, M.; Kocjan, R. Differences in Trace Metal Concentrations (Co, Cu, Fe, Mn, Zn, Cd, and Ni) in Whole Blood, Plasma, and Urine of Obese and Nonobese Children. Biol. Trace Elem. Res. 2013, 155, 190-200. [CrossRef]

10. Yerlikaya, F.H.; Toker, A.; Arıbaş, A. Serum trace elements in obese women with or without diabetes. Indian J. Med. Res. 2013, 137, 339-345.

11. Lee, Y.-A.; Kim, S.-H.; Kim, H.-N.; Song, S.-W. Are There Differences in Hair Mineral Concentrations Between Metabolically Healthy and Unhealthy Obese Adults? Biol. Trace Elem. Res. 2019, 193, 311-318. [CrossRef] [PubMed]

12. Xu, Y.; Wei, Y.; Long, T.; Wang, R.; Li, Z.; Yu, C.; Wu, T.; He, M. Association between urinary metals levels and metabolic phenotypes in overweight and obese individuals. Chemosphere 2020, 254, 126763. [CrossRef]

13. Suliburska, J.; Bogdański, P.; Pupek-Musialik, D.; Krejpcio, Z. Dietary Intake and Serum and Hair Concentrations of Minerals and their Relationship with Serum Lipids and Glucose Levels in Hypertensive and Obese Patients with Insulin Resistance. Biol. Trace Elem. Res. 2010, 139, 137-150. [CrossRef] [PubMed]

14. Nikonorov, A.A.; Skalnaya, M.G.; Tinkov, A.A.; Skalny, A.V. Mutual interaction between iron homeostasis and obesity pathogenesis. J. Trace Elem. Med. Biol. 2015, 30, 207-214. [CrossRef] [PubMed]

15. Thethi, T.K.; Parsha, K.; Rajapurkar, M.; Mukhopadhyay, B.; Shah, S.; Yau, C.L.; Japa, S.; Fonseca, V. Urinary Catalytic Iron in Obesity. Clin. Chem. 2011, 57, 272-278. [CrossRef] [PubMed]

16. Yang, H.; Liu, C.-N.; Wolf, R.M.; Ralle, M.; Dev, S.; Pierson, H.; Askin, F.; Steele, K.E.; Magnuson, T.H.; Schweitzer, M.A.; et al. Obesity is associated with copper elevation in serum and tissues. Metallomics 2019, 11, 1363-1371. [CrossRef] [PubMed]

17. Tinkov, A.A.; Polyakova, V.S.; Nikonorov, A.A. Chronic administration of iron and copper potentiates adipogenic effect of high fat diet in Wistar rats. BioMetals 2013, 26, 447-463. [CrossRef] [PubMed]

18. Skalnaya, M.G.; Skalny, A.V.; Tinkov, A.A. Serum copper, zinc, and iron levels, and markers of carbohydrate metabolism in postmenopausal women with prediabetes and type 2 diabetes mellitus. J. Trace Elem. Med. Biol. 2017, 43, 46-51. [CrossRef]

19. Mokhberi, V.; Bagheri, B.; Akbari, N.; Tabiban, S.; Habibi, V. Serum level of copper in patients with coronary artery disease. Niger. Med. J. 2015, 56, 39-42. [CrossRef]

20. Burkhead, J.L.; Lutsenko, S. The role of copper as a modifier of lipid metabolism. In Lipid Metabolism; Baez, R.V., Ed.; IntechOpen: London, UK, 2013; pp. 39-60.

21. Darroudi, S.; Saberi-Karimian, M.; Tayefi, M.; Tayefi, B.; Khashyarmanesh, Z.; Fereydouni, N.; Haghighi, H.M.; Mahmoudi, A.A.; Kharazmi-Khorassani, J.; Gonoodi, K.; et al. Asso-ciation between hypertension in healthy participants and zinc and copper status: A population-based study. Biol. Trace Elem. Res. 2019, 190, 38-44. [CrossRef]

22. Li, Z.; Wang, W.; Liu, H.; Li, S.; Zhang, D. The association of serum zinc and copper with hypertension: A meta-analysis. J. Trace Elem. Med. Biol. 2019, 53, 41-48. [CrossRef]

23. Stoffaneller, R.; Morse, N.L. A Review of Dietary Selenium Intake and Selenium Status in Europe and the Middle East. Nutrients 2015, 7, 1494-1537. [CrossRef] [PubMed]

24. Vinceti, M.; Filippini, T.; Rothman, K.J. Selenium exposure and the risk of type 2 diabetes: A systematic review and meta-analysis. Eur. J. Epidemiol. 2018, 33, 789-810. [CrossRef] [PubMed]

25. Zhou, J.; Huang, K.; Lei, X.G. Selenium and diabetes-Evidence from animal studies. Free. Radic. Biol. Med. 2013, 65, 1548-1556. [CrossRef]

26. Kim, H.-N.; Song, S.-W. Concentrations of Chromium, Selenium, and Copper in the Hair of Viscerally Obese Adults are Associated with Insulin Resistance. Biol. Trace Elem. Res. 2014, 158, 152-157. [CrossRef]

27. Stupin, A.; Cosic, A.; Novak, S.; Vesel, M.; Jukic, I.; Popovic, B.; Karalic, K.; Loncaric, Z.; Drenjancevic, I. Reduced Dietary Selenium Impairs Vascular Function by Increasing Oxidative Stress in Sprague-Dawley Rat Aortas. Int. J. Environ. Res. Public Health 2017, 14, 591. [CrossRef] 
28. Tinkov, A.A.; Skalnaya, M.G.; Ajsuvakova, O.P.; Serebryansky, E.P.; Chao, J.C.-J.; Aschner, M.; Skalny, A.V. Selenium, Zinc, Chromium, and Vanadium Levels in Serum, Hair, and Urine Samples of Obese Adults Assessed by Inductively Coupled Plasma Mass Spectrometry. Biol. Trace Elem. Res. 2021, 199, 490-499. [CrossRef] [PubMed]

29. Król, E.; Bogdański, P.; Suliburska, J.; Krejpcio, Z. The Relationship between Dietary, Serum and Hair Levels of Minerals (Fe, $\mathrm{Zn}, \mathrm{Cu}$ ) and Glucose Metabolism Indices in Obese Type 2 Diabetic Patients. Biol. Trace Elem. Res. 2019, 189, 34-44. [CrossRef] [PubMed]

30. Olechnowicz, J.; Tinkov, A.; Skalny, A.; Suliburska, J. Zinc status is associated with inflammation, oxidative stress, lipid, and glucose metabolism. J. Physiol. Sci. 2018, 68, 19-31. [CrossRef]

31. Khorsandi, H.; Nikpayam, O.; Yousefi, R.; Parandoosh, M.; Hosseinzadeh, N.; Saidpour, A.; Ghorbani, A. Zinc supplementation improves body weight management, inflammatory biomarkers and insulin resistance in individuals with obesity: A ran-domized, placebo-controlled, double-blind trial. Diabetol. Metab. Syndr. 2019, 11, 101. [CrossRef]

32. Williams, C.R.; Mistry, M.; Cheriyan, A.M.; Williams, J.M.; Naraine, M.K.; Ellis, C.L.; Mallick, R.; Mistry, A.C.; Gooch, J.L.; Ko, B.; et al. Zinc deficiency induces hypertension by promoting renal Na+ reabsorption. Am. J. Physiol. Renal. Physiol. 2019, 316, F646-F653. [CrossRef] [PubMed]

33. Treviño, S.; Diaz, A. Vanadium and insulin: Partners in metabolic regulation. J. Inorg. Biochem. 2020, 208, 111094. [CrossRef] [PubMed]

34. Tinkov, A.A.; Popova, E.V.; Polyakova, V.S.; Kwan, O.V.; Skalny, A.V.; Nikonorov, A.A. Adipose tissue chromium and vanadium disbalance in high-fat fed Wistar rats. J. Trace Elem. Med. Biol. 2015, 29, 176-181. [CrossRef]

35. Zhang, S.; Yan, L.; Kim, S.M. Vanadium-protein complex inhibits human adipocyte differentiation through the activation of $\beta$-catenin and LKB1/AMPK signaling pathway. PLoS ONE 2020, 15, e239547. [CrossRef] [PubMed]

36. Park, S.-J.; Youn, C.-K.; Hyun, J.W.; You, H.J. The Anti-obesity Effect of Natural Vanadium-Containing Jeju Ground Water. Biol. Trace Elem. Res. 2012, 151, 294-300. [CrossRef] [PubMed]

37. Bravo-Sagua, R.; Reyes, M.; Lavandero, S.; Cifuentes, M. Calcium in Obesity and Related Diseases: The Calcium-Sensing Receptor as a Novel Mediator. In Molecular, Genetic, and Nutritional Aspects of Major and Trace Minerals; Academic Press: Cambridge, MA, USA, 2017; pp. 35-44.

38. Li, P.; Fan, C.; Lu, Y.; Qi, K. Effects of calcium supplementation on body weight: A meta-analysis. Am. J. Clin. Nutr. 2016, 104, 1263-1273. [CrossRef] [PubMed]

39. Zhang, F.; Ye, J.; Zhu, X.; Wang, L.; Gao, P.; Shu, G.; Jiang, Q.; Wang, S. Anti-Obesity Effects of Dietary Calcium: The Evidence and Possible Mechanisms. Int. J. Mol. Sci. 2019, 20, 3072. [CrossRef] [PubMed]

40. Das, S.; Choudhuri, D. Dietary calcium regulates the insulin sensitivity by altering the adipokine secretion in high fat diet induced obese rats. Life Sci. 2020, 250, 117560. [CrossRef]

41. Cruz, K.J.; De Oliveira, A.R.; De Freitas, S.T.; Henriques, G.S.; Marreiro, D.D.N. Hypomagnesemia in Obese Subjects: Evidence of Systematic Review and Meta-analysis. Curr. Nutr. Food Sci. 2020, 16, 1044-1051. [CrossRef]

42. Huerta, M.G.; Roemmich, J.N.; Kington, M.L.; Bovbjerg, V.E.; Weltman, A.L.; Holmes, V.F.; Patrie, J.T.; Rogol, A.D.; Nadler, J.L. Magnesium Deficiency Is Associated with Insulin Resistance in Obese Children. Diabetes Care 2005, 28, 1175-1181. [CrossRef]

43. Kostov, K. Effects of Magnesium Deficiency on Mechanisms of Insulin Resistance in Type 2 Diabetes: Focusing on the Processes of Insulin Secretion and Signaling. Int. J. Mol. Sci. 2019, 20, 1351. [CrossRef]

44. Castellanos-Gutiérrez, A.; Sánchez-Pimienta, T.G.; Carriquiry, A.; Da Costa, T.H.M.; Ariza, A.C. Higher dietary magnesium intake is associated with lower body mass index, waist circumference and serum glucose in Mexican adults. Nutr. J. 2018, 17, 114. [CrossRef] [PubMed]

45. Guerrero-Romero, F.; Rodriguez-Moran, M. Serum magnesium in the metabolically-obese normal-weight and healthy-obese subjects. Eur. J. Intern. Med. 2013, 24, 639-643. [CrossRef] [PubMed]

46. Schutten, J.C.; Joosten, M.M.; De Borst, M.H.; Bakker, S.J. Magnesium and Blood Pressure: A Physiology-Based Approach. Adv. Chronic Kidney Dis. 2018, 25, 244-250. [CrossRef] [PubMed]

47. Chojnacka, K.; Mikulewicz, M. Biomarkers of Trace Element Status. In Recent Advances in Trace Elements; Chojnacka, K., Saeid, A., Eds.; John Wiley \& Sons Ltd.: Hoboken, NJ, USA, 2018; pp. 457-467. 